\title{
Analytical Determination of Antihestamine drugs Pure and its pharmaceutical Preparation with NBSA reagent
}

\author{
Afshan Suraiya ${ }^{*}$, Pratibha Singh, Siddharth Singh and R. P. S. Chauhan* \\ *Dept. of Chemistry, G. B. M. College, Gaya \\ *P. G. Dept. of Chemistry, Gaya College, Gaya (Magadh University) Gaya -823001
}

\begin{abstract}
A quick and convenient method has been developed for the micro estimation of antihistamine drugs. $1-5 \mathrm{mg}$ of sample is allowed to react with $10 \mathrm{ml}$ of $0.02 \mathrm{M}$, N-bromosaccharin solution. Unconsumed reagent can be accurately titrated with $5 \mathrm{ml}$ of $15 \% \mathrm{KI}$ and $0.02 \mathrm{~N}$ sodium thiosulphate solution using starch as indicator. $S D$ and $C V$ was calculated for reproducible and accurate result. The accuracy of the method is within \pm 1 $\%$ and possible course of reaction was suggested on the basis of stoichiometry as well as find reaction product.
\end{abstract}

Keywords: Determination, Antihestamine, NBSA, Pharmaceutical preparation

\section{Introduction}

Antihistamine drug ${ }^{1-4}$ is one that inhibits, sharpens or alters nature of emotional and behavioral responses. These drugs have also been employed for the symptomatic treatment of neurotic and psychotic conditions. These drugs are administered orally because of the great medicinal importance the analysis and assay of antihistamines need prime attention. Several workers have reported the pharmacology and determination of phenothiazine derivatives ${ }^{5-12}$ the N-halo saccharin reagents are stable and determine different compounds ${ }^{13-15}$ in different reaction conditions. Singh et al. ${ }^{16}$ determine antihistamine drugs pure and its pharmaceutical preparations with $\mathrm{BrCl}$ reagent in acetic acid medium. The present method is better than the existing methods and does not require a catalyst and sophisticated instrumentation.

\section{Materials \& Method}

2.1 Reagent: 0.05240 of N-bromosaccharin (NBSA) was accurately weighed and dissolved in $40 \mathrm{ml}$ of glacial acetic acid by shaking thoroughly in $100 \mathrm{ml}$ volumetric flask. The solution was made up to the mark with distilled water and standardized iodometrically ${ }^{17}$

A stock solution of sodium thiosulphate was prepared by dissolving 4.9604. $\mathrm{g}$ of sodium thiosulphate in distilled water in a $1 \mathrm{~L}$ volumetric flask. The solution was standardized with $0.02 \mathrm{~N}$ copper sulphate iodometrically.

2.2 Sample solution: Stock solution of all phenothiazine derivatives were prepared by dissolving $50 \mathrm{mg}$ accurately weighed amount of the sample in distilled water in $50 \mathrm{ml}$ standard volumetric flask.

2.3 Method: At aliquots containing 1-5 mg of sample from the stock solution was transferred to a $100 \mathrm{ml}$ glass stopper conical flask. $10 \mathrm{ml}$ of N-Bromosaccharin solution was added. The flask was Stoppard and contents shaken thoroughly. The reaction was allowed to proceed for 10 minutes at room temperature with occasional shaking The stopper was washed with $5 \mathrm{ml}$ of distilled water followed by addition $5 \mathrm{ml}$ of $15 \% \mathrm{KI}$ solution. The contents were shaken thoroughly and liberated iodine was titrated against standard sodium thiosulphate solution using starch as indicator. A blank experiment was also run under identical experimental conditions.

Recovery of sample (mg)

$$
\left(\mathrm{V}_{\mathrm{B}}-\mathrm{V}_{\mathrm{S}}\right) \mathrm{n} \times \mathrm{W}
$$

Where $\quad \mathrm{VB}=$ Volume of sodium thiosulphate solution required to titrate blank $(\mathrm{ml})$

VS $=$ Volume of sodium thiosulphate solution required to titrate samples $(\mathrm{ml})$

$\mathrm{N} \quad=$ Normality of sodium thiosulphate solution.

$\mathrm{W}=$ Molecular Weight of sample

$\mathrm{N}=$ Stoichiometry 
With recommended procedure the determination of Prochloroperazine Maleate (Pure) Promethazine hydrochloride (Pure), Trifluopromazine hydrochloride (pure), Trifluoperazine (Pure) \& eskazine (tab) has been successfully achieved on 1-5 mg of sample within an accuracy of $\pm 1 \%$ (Table-1 ) in most of the cases.

\section{Figures \& Tables}

A quick and convenient method has been developed for the micro estimation of antihistamine drugs. 1$5 \mathrm{mg}$ of sample is allowed to react with $10 \mathrm{ml}$ of $0.02 \mathrm{M}, \mathrm{N}$-bromosaccharin solution. Unconsumed reagent can be accurately titrated with $5 \mathrm{ml}$ of $15 \% \mathrm{KI}$ and $0.02 \mathrm{~N}$ sodium thiosulphate solution using starch as indicator. SD and CV was calculated for reproducible and accurate result. The accuracy of the method is within $+1 \%$ and possible course of reaction was suggested on the basis of stoichiometry as well as find reaction product.<smiles>[R]c1ccc2c(c1)N([R])c1ccc([R])cc1N([R])c1ccccc1Sc1ccccc1C(=O)N[C@H]2C</smiles>

Where $\mathrm{R}_{1}=\mathrm{Cl}, \mathrm{R}_{2}=-\mathrm{CH}_{2}\left(\mathrm{CH}_{2}\right)_{2}-\mathrm{N}\left(\mathrm{CH}_{3}\right)_{2}$

TABLE - 1

Determination of Antihistamine drugs with 0.2M NBSA

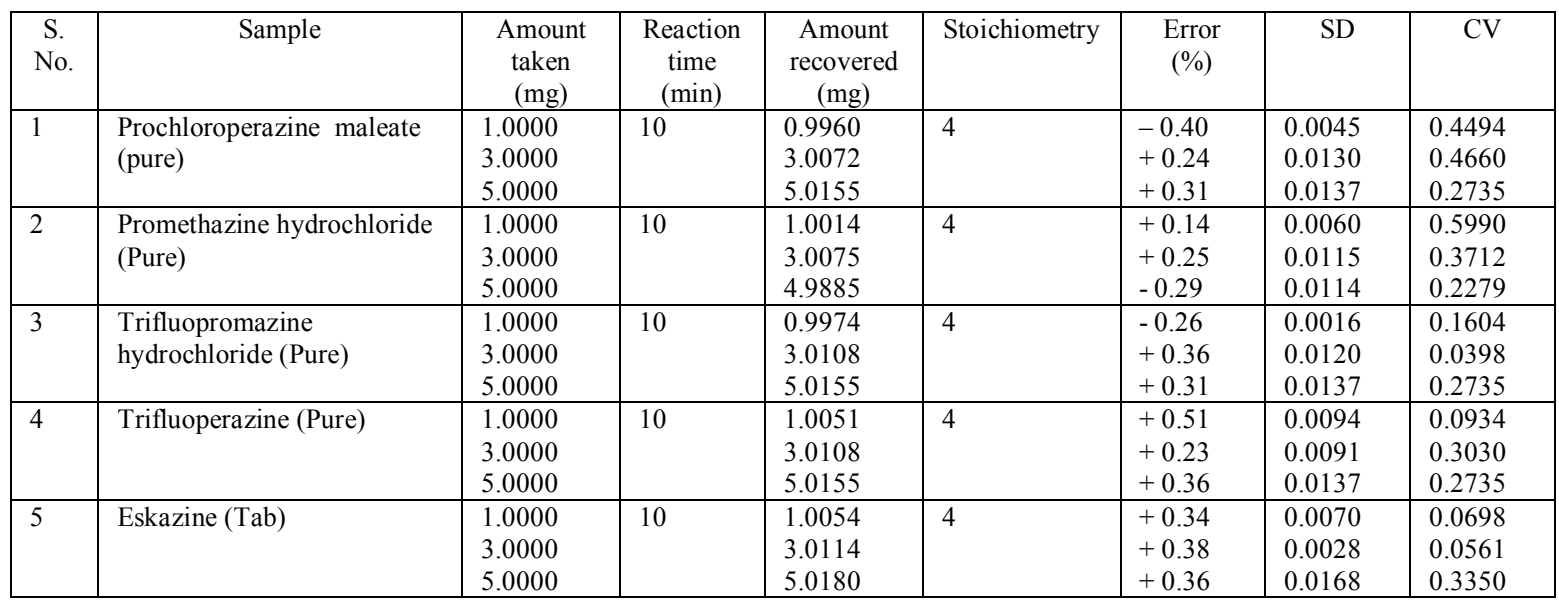

In each case three determinations were done. 


\section{Conclusion}

The effect of variables such as reaction time, concentration of reagent and temperature were studied. It was found that the recommended concentration of NBSA reagent is suitable to achieve quantitative reaction. It was observed that the reaction was completed at room temperature. Accurate and constant results were obtained when the reaction was carried out at room temperature and normally the reaction is completed with 10 minutes. Considering the stoichiometry and the available literature it may be believed that prochloroperazine maleate forms their monosulphoxide derivative with NBSA reagent.

\section{References}

[1]. R.Gasa, , Application of some medicinal compounds J. Pharmac. Chemother, 17 1961,442

[2]. United States Pharma copacia XVIII 423.

[3]. J. J.Lewis An introduction of pharma colosy, London, 1961, 251

[4]. Goodmans \& Galimann, Pharmacolosical basis of therepentia IV Ed.

[5]. Chignell C. F. Method's in pharmacolony 22, 1970199

[6]. S. H. Curry, determination of some medicinal compounds J. Pharm Pharmac 22, 1970199

[7]. $\quad$ L. A. Luzzi,Application of some pharmaceutical compounds J. Pharm. Sci. 62, 19731261

[8]. E.Davis, application of some organic compounds with Brcl Clin, Chin Acta 38(2) 1972, 265

[9]. B. M. Alture, Ph. D. Thesis New York University.

[10]. B. M. Alture, Kinetic study for some organic compound Fedn. Proc. Fedn. Aim. Soce Exp. Biol. 23, 1964, 252

[11]. T. J. Haley, Phermc. Exp. thesis, 100, 1950, 393

[12]. H. A. Zarem. J. Physiol, Application of some medicinal organic compound with NBCA, 212, 1967, 1081

[13]. RPS Chauhan, V. K. Dubey \& U. B. Singh, Analytical studies for determination of some anti histamine drugs with V(V) reagent Asian J. of Chemistry 6, 1994, 665

[14]. RPS Chauhan, J. K. Verma, A. Nigam, S. K. Nigam and M. U. Khan Kinetic study for the determination of some aldehydes with Nchlro saccharaine, Oxid. Comm. 18, 1995, 304

[15]. L. Harihar, M. R. Kembhavi and S. T. Wandibewoor, Determination of some hydrazine J. Ind. Chem. Soc. 76, 1999, 128

[16]. R. P. S . Chauhan., and Singh M. P. Determination of anti histamine drugs with Brcl, Acta Ciencia Indica Vol XIXC , 1993,112

[17]. Barakat M. Z. Application of N-chlro saccarin reagent, Anal. Chem. 26 1954, 1973 